\title{
Synergy between Sentinel-1 radar time series and Sentinel-2 optical for the mapping of restored areas in Danube delta
}

\author{
Simona Niculescu, ${ }^{\mathrm{a}}$ Cédric Lardeux, ${ }^{\mathrm{b}}$ Jenica Hanganu ${ }^{\mathrm{c}}$ \\ ${ }^{a}$ Laboratoire LETG-Brest, Géomer, UMR 6554 CNRS, IUEM •UBO, rue Dumont d'Urville, F-29280 Plouzané, France, \\ simona.niculescu@univ-brest.fr \\ ${ }^{b}$ Office National des Forêts 2, avenue de Saint-Mandé, F-75570 Paris Cedex 12,France, clardeux@gmail.com \\ ${ }^{c}$ Danube Delta National Institute for Research and Development. Str. Babadag, $n^{\circ} 165$, 820112, Tulcea, Romania, \\ jenicahanganu@ddni.ro
}

\begin{abstract}
Wetlands are important and valuable ecosystems, yet, since 1900, more than 50\% of wetlands have been lost worldwide. An example of altered and partially restored coastal wetlands is the Danube Delta in Romania. Over time, human intervention has manifested itself in more than a quarter of the entire Danube surface. This intervention was brutal and has rendered ecosystem restoration very difficult. Studies for the rehabilitation / re-vegetation were started immediately after the Danube Delta was declared as a Biosphere Reservation in 1990. Remote sensing offers accurate methods for detecting and mapping change in restored wetlands. Vegetation change detection is a powerful indicator of restoration success. The restoration projects use vegetative cover as an important indicator of restoration success. To follow the evolution of the vegetation cover of the restored areas, satellite images radar and optical of last generation have been used, such as Sentinel-1 and Sentinel-2. Indeed the sensor sensitivity to the landscape depends on the wavelength what- ever radar or optical data and their polarization for radar data. Combining this kind of data is particularly relevant for the classification of wetland vegetation, which are associated with the density and size of the vegetation. In addition, the high temporal acquisition frequency of Sentinel-1 which are not sensitive to cloud cover al- low to use temporal signature of the different land cover. Thus we analyse the polarimetric and temporal signature of Sentinel-1 data in order to better understand the signature of the different study classes. In a second phase, we performed classifications based on the Random Forest supervised classification algorithm involving the entire Sentinel-1 time series, then starting from a Sentinel-2 collection and finally involving combinations of Sentinel-1 and -2 data.
\end{abstract}

Keywords: cartography, coastal wetlands, Danube delta, alteration and remediation of ecosystems, remote sensing

\section{Remote sensing and restoring wetland habitats}

Wetland habitat is being restored throughout the world (Zedler \& Kercher, 2005); however, achieving conservation goals and objectives requires knowledge of vegetation composition, structure, and change over time with respect to attributes such as percent cover, biomass, and plant diversity (Phinn et al. 1999). Therefore, there is a need to further develop, refine, and disseminate siteand landscape-level monitoring methods (Simenstad et al., 2006). Having developed criteria for selecting wetland sites to be restored or enhanced, wetland managers must prioritize the sites based on ecological and economic considerations (Klemas, 2013). Remote sensing techniques can provide a cost-effective means for selecting restoration sites and observing their progress over time.

Remote sensing involves the acquisition of information about the Earth's surface at a remote distance, usually by airplane or satellite (Jensen 2000). It offers tools to map, measure, model, and evaluate wetland restoration efforts in a cost-effective manner. The use of this technology in the ecological sciences is rapidly increasing because ecosystems such as wetlands can be monitored at various spatial and temporal scales (Jensen et al. 1995; Guo \& Psuty 1997; Michener \& Houhoulis 1997; Apan et al. 2002; Heinl et al. 2006; Papa et al. 2006; Niculescu et al., 2016).

Despite the increasing use of remote sensing for wetland inventory and monitoring, there has been limited use of this technology in the restoration of wetlands (Phinn et al. 1999; Hinkle \& Mitsch 2005). Remote sensing is ideal for monitoring restored wetlands because it provides a high spatial and temporal intensity of measurements in relatively inaccessible and sensitive sites without the potential invasiveness that traditional field methods present to delicate habitat conditions, bird- nesting territories, and endangered species habitat (Schuman and Ambrose, 2003). In an ideal situation, remotely sensed images are acquired when decisions can be made about imagery specifications and field data collection that will make change detection accurate and applicable to the monitoring of a restoring wetland.

Recent advancements in imaging science have provided finer spatial, spectral, and temporal resolution as well as reduced price. In addition, non-optical data sources such as radar data (e.g., SAR, RADAR) and laser altimetry (e.g., LiDAR), have been shown to add value when combined with optical remote sensing data (Ramsey et al. 
1998; Rosso et al. 2005b; Niculescu et al., 2016). Change detection is an important tool for wetland restoration monitoring because it provides measurements of incremental changes that can be used for inventory and benchmark purposes; knowledge of these changes can then be integrated with adaptive management plans and used to target specific restoration goals (Tuxen et al., 2008).

The success of restoration, however, is difficult to assess. The degree of success for many of these restoration sites is still being debated, especially since there is no full agreement on criteria used to measure success. The creation, enhancement, or restoration of coastal habitats requires much time and constant attention (Klemas, 2013). Remote sensing offers accurate automated methods for detecting change in restored wetlands. Vegetation change detection is a powerful indicator of restoration success. The restoration projects use vegetative cover as an important indicator of restoration success.

Synthetic aperture radar (SAR) technology provides the increased spatial resolution that is necessary in regional wetland mapping, and SAR data have been used extensively for this objective (Bourgeau-Chavez et al., 2005; Lang and McCarty, 2008; Novo et al., 2002). Radar has the capability of penetrating the plant cover canopy and detecting submerged sectors and soil surface moisture. Although the spatial resolution of radar images does not allow thorough and detailed habitat map- ping, these images are useful for mapping wetland vegetation. The radar polarimetry and polarimetric parameters contribute significantly to the improvement of vegetation identification based on polarization channels. Multipolarization and multi- frequency radar devices are also used for the classification of wetland vegetation depending on their wavelengths, polarizations and backscattering mechanisms and can be used to estimate the density and size of the vegetation. Microwave radiation polarization, like radar beam incidence angle and wave frequency, has long been acknowledged as an important parameter for object recognition and understanding object features. Access to the scattering matrix permits several analytical approaches and hence various ways of assessing the potential of multi-polarized radar images. One approach consists of synthesizing pixel-based signal strength, which should have been measured at the same frequency for any polarization configuration (linear and/or circular) (Niculescu et al., 2015). The sensitivity of microwave en- ergy to water and its ability to penetrate vegetative canopies makes SAR ideal for the detection of the hydrologic features under vegetation.

SAR image time series such as those provided by the Sentinel-1 satellite allow significant improvements in vegetation classification. The key advantage of satelliteborne SAR imaging is its independence of cloud cover, and because it is an active sensing system, its independence of sun-induced reflection. Consequently, SAR imagery has become an important tool for distinguishing different vegetation classes. Recently, polarimetric SAR images have been analyzed using decomposition theorems such as alpha/entropy decomposition, which increases the accuracy of vegetation analysis from microwave data. However, there is a wide choice of remote-sensing satellites, radar, and optical. Whereas optical satellites usually operate in one imaging mode, radar satellites can be programmed to work indifferent configurations. The user must choose the polarization configuration, the incidence angle, and the spatial resolution associated with the chosen imaging mode. Combined approaches of using optical and microwave images can improve the vegetation analysis.

Airborne laser instruments such as LiDAR represent innovative tools for management applications, including flood zone delineation, monitoring beach nourishment projects, and mapping vegetation (Niculescu et al., 2016) and changes along sandy coasts and shallow benthic environments due to storms or long-term sedimentary processes (Klemas, 2013). Identifying potential restoration sites and prioritizing them using ecological and economic criteria is by no means a simple task (Russell, Hawkins, and O’Neill, 2004; Thayer, 1992; White and Fennessy, 2005). The combined use of LIDAR, radar, and multispectral imagery can improve the accuracy of monitoring vegetation species discrimination and provide a better understanding of the topography/bathymetry and hydrologic conditions.

\section{Dataset}

We used the following satellite images in this study: 20 Sentinel-1 images acquired between 9.10.2014 and 01.04.2016 (table 2) and one Sentinel-2 image acquired on

28.04.2016 in the restored areas in the northern part of the delta (Babina and Cernovca). The Sentinel-1 data were acquired in a time series that covered the entire growth season of 2015 and part of 2016. This enabled us to determine the influence of the time dimension and of the polarimetric dimension ( $\mathrm{VV}$ and $\mathrm{VH}$ polarization are available) on the characterization and classification of the vegetation in the restored delta areas. 


\begin{tabular}{|l|l|l|}
\hline Date & Incidence & Orbit \\
\hline $09-10-2014$ & 38.055 & Ascending \\
\hline $02-11-2014$ & 38.786 & Descending \\
\hline $26-11-2014$ & 38.653 & Descending \\
\hline $13-01-2015$ & 39.215 & Ascending \\
\hline $26-03-2015$ & 39.856 & Ascending \\
\hline $07-04-2015$ & 38.569 & Ascending \\
\hline $01-05-2015$ & 38.421 & Descending \\
\hline $13-05-2015$ & 39.654 & Descending \\
\hline $30-06-2015$ & 39.478 & Ascending \\
\hline $05-08-2015$ & 38.665 & Descending \\
\hline $17-08-2015$ & 37.789 & Descending \\
\hline $29-08-2015$ & 38.669 & Ascending \\
\hline $10-09-2015$ & 39.285 & Descending \\
\hline $22-09-2015$ & 39.456 & Ascending \\
\hline $09-11-2015$ & 38.721 & Descending \\
\hline $03-12-2015$ & 38.451 & Ascending \\
\hline $27-12-2015$ & 39.885 & Ascending \\
\hline $20-01-2016$ & 38.411 & Descending \\
\hline $13-02-2016$ & 39.662 & Ascending \\
\hline $01-04-2016$ & 39.453 & Ascending \\
\hline
\end{tabular}

Table 1: Sentinel-1 imagery used in this study

Since it was first launched in April 2014, the Sentinel-1 satellite has allowed specialists to monitor the earth's surface day and night regardless of weather conditions and has transmitted high-resolution space images free of charge. The Sentinel 1 SAR mission is part of the Copernicus Programme - European Earth Observation Programme, which was previously called GMES (Global Monitoring for Environment and Security), of the European Space Agency. Placed on an orbit at an altitude of $693 \mathrm{~km}$, Sentinel-1 operates in four data collection modes: the StripMap (SM) mode, the Interferometric Wide swath (IW) mode, the Extra-Wide swath (EW) mode and the Wave (WV) mode. Each mode provides different products with respect to spatial resolution and imaging swath. Sentinel-1 images are captured in $\mathrm{C}$ band $(5.5 \mathrm{~cm})$, and they may exhibit simple $\mathrm{HH}$ or $\mathrm{VV}$ polarization or double $\mathrm{HH}+\mathrm{HV}$ or $\mathrm{VH}+\mathrm{VV}$ polarization. The data used in our research were collected in the IW mode. This mode includes three sub-swaths, namely IW1, IW2 and IW3, which correspond to cyclical antenna deviations. This mode provides GRD (Ground Range Multilook Detected) and SLC (Single Look Complex) images made up of three IW (MDA, 2011). The GRD images are Multilook images (five looks for the IW mode) with less speckle noise and coarser space resolution. Although the SLC products have finer resolution, it is difficult to use them directly due to the phase information, which seems useless as it prevents extraction of additional information in certain cases.

GRD image calibration is vital for viewing the maximum amount of information on an image. In our research, the o 0 value is extracted using Calibration Tools of the OrfeoToolbox software, which provides us with the backscattering coefficient of the area. These values depend on the targets illuminated by the beam, on ground roughness and moisture and, in the end, on the vegetation density.

Sentinel-2A is the second satellite of Europe's Copernicus Programme, following the Sentinel-1A radar satellite launched last year. In partnership with the European Commission and within the frame of the Global Monitoring for Environment and Security (GMES) program, the European Space Agency (ESA) is developing the Sentinel-2 optical imaging mission, which is devoted to the operational monitoring of land and coastal areas. Sentinel-2 is the operational mission devoted to the observation of continental surfaces in decametric resolution. The Sentinel-2 mission ensures a systematic full land cover with 10-day repetitiveness by a single satellite and 5-day repetitiveness by two satellites. Sentinel-2 has 13 spectral bands, 3 of which are in the near infrared (SWIR). These images have a $290-\mathrm{km}$-wide field of view and $10-\mathrm{m}, 20-\mathrm{m}$ or $60-\mathrm{m}$ resolution depending on the spectral bands. The Sen- tinel-2 mission is a land and coastal areas monitoring constellation of two satellites (Sentinel-2A, which was launched on 23 June 2015, and Sentinel-2B, which will follow in the second half of 2016) that provide high-resolution optical imagery and continuity for the current SPOT and Landsat missions. The mission will provide global coverage of the Earth's land surface every 10 days with one satellite and every 5 days with 2 satellites, making the data of great use in ongoing studies. Sen- tinel-2 delivers highresolution optical images for land monitoring, emergency response and security services. The satellite carries a multispectral imager with a swath of $290 \mathrm{~km}$. The imager provides a versatile set of 13 spectral bands spanning from the visible and near infrared to the shortwave infrared, featuring four spectral bands at $10-\mathrm{m}$, six bands at $20-\mathrm{m}$ and three bands at $60-\mathrm{m}$ spatial resolution. The imager's 13 spectral bands, from the visible and the near infrared to the shortwave infrared at different spatial resolutions, take land monitoring to an unprecedented level. In fact, Sentinel-2 is the first optical Earth observation mission of its type to include three bands in the 'red edge', which provides key information on the state of vegetation. The 13 spectral bands span from the visible and the near infrared to the short-wave infrared. The 4 bands at $10 \mathrm{~m}$ are the classical blue $(490 \mathrm{~nm})$, green $(560 \mathrm{~nm})$, red $(665 \mathrm{~nm})$ and near infrared $(842 \mathrm{~nm})$ bands dedicated to land applications. The 6 bands at $20 \mathrm{~m}$ include 4 narrow bands in the vegetation red edge spectral domain $(705 \mathrm{~nm}, 740 \mathrm{~nm}, 775 \mathrm{~nm}$ and $865 \mathrm{~nm})$ and 2 large SWIR bands (1610 $\mathrm{nm}$ and $2190 \mathrm{~nm}$ ) dedicated to snow/ice/cloud detection and to vegetation moisture stress assessment. The 3 bands at $60 \mathrm{~m}$ are dedicated to atmospheric correction (443 nm for aerosols and $940 \mathrm{~nm}$ for water vapor) and to cirrus detection (1380 $\mathrm{nm}$ ) (Baillarin et al., 2012).

\section{Cartography and Remote-sensing methodology}

The chosen methodology is associated with multi-data radar and optical image classification methodology. We 
began with the preliminary processing of the radar and optical images (Figures 1 and 2 show the radar data).

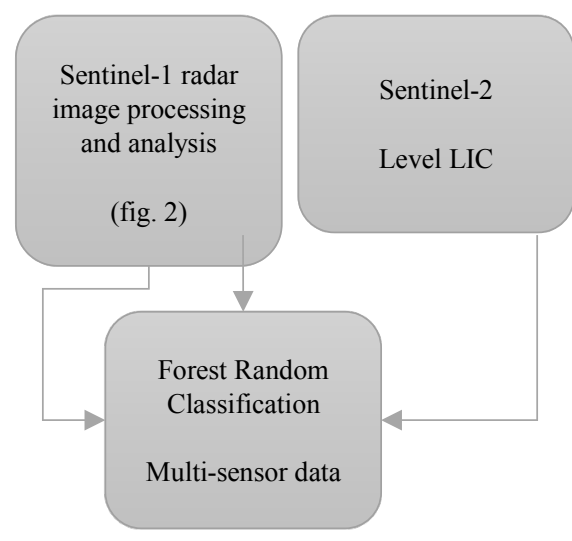

Fig. 1. Data processing procedure

A typical processing sequence applied to SAR data entails radiometric calibration, speckle filtering, and orthorectification. Radar signals require pre-processing to account for geometric distortions and for differences in illumination conditions due to topography and the surface being illuminated to one side of the satellite. An additional step is needed to remove noise caused by reflections from features that are not of interest. This is called speckle noise and is removed by a process called speckle filtering. The filtering applied is filtering of the Lee type (Figure 14). Adaptive filters use local statistics to filter the data and so reduce image speckle and, in some cases, preserve or enhance edges and other features. At the same time, the backscattering coefficient was analyzed for the two different polarizations depending on a set of parameters related, on the one hand, to the RSO characteristics (acquisition frequency, polarization and geometry) and, on the other hand, to the at- tributes of the target (geometric structure, dielectric constant, biomass, etc.). The backscattering coefficient is usually expressed in decibels $(\mathrm{dB})$, yielding a normalized value comparing the observed power to the rated power for an equivalent $1-\mathrm{m} 2$ surface and corresponding to the distance to the ground. The backscattering coefficient is also very much influenced by factors related to the sensor configuration and collection geometry.

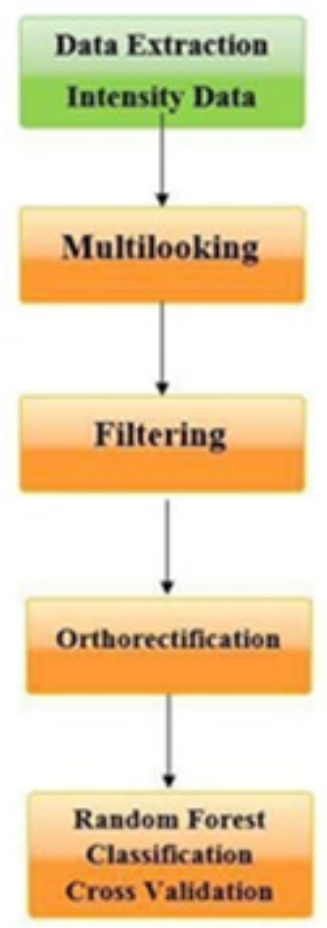

Figure 2: Radar data processing procedure

The optical image (Sentinel-2) was already orthorectified in the UTM $35 \mathrm{~N}$ cartographic system by ESA (level 1C). The geometric correction of image data is an important prerequisite that must be performed prior to using images in geographic information systems (GIS) and other image-processing programs. To process the data with other data (radar) or maps in a GIS, all the data must be based on the same reference system. Using a combination of different sensors, we resampled the data to the smallest pixel size between optical and radar. All the datasets were orthorectified, resampled to a $10-\mathrm{m}$ pixel size and separately classified.

We then performed synthetic Random Forest classifications, first for all the Sen- tinel-1 radar data and then using combinations of the Sentinel-2 image. The super- vised classifier used is the Random Forest algorithm, which is available in OrfeoToolbox (version 5.0) free software. Random Forests offers high-quality map- ping of different vegetation types with much faster computation compared to other state-of-the-art classifiers such as, for instance, Support Vector Machines with Gaussian kernels (Inglada et al., 2016). Random Forest is an ensemble learning technique and builds upon multiple decision trees. Each decision tree is built using a subset of the original training data and is evaluated based on the remaining training features. New objects are classified as the class that is predicted by the most trees. According to Rodriguez-Galiano et al., 2012, the classifier has three main ad- vantages for land cover classifications from remote-sensing images: (i) it reaches higher accuracies than other machine-learning classifiers; (ii) it has the ability to measure the importance level of the input images; (iii) it makes no assumptions about the distributions of the input images (cited by Hütt et al., 2016). We use the following parameters for the Random 
Forest algorithm: 100 trees, maximum depth of the tree 25 and minimum number of samples in each node 25 .

The final stage of image processing relates to the integration of several images from two satellites (Sentinel-1 and Sentinel-2), which have different spatial resolutions. Image integration is a method for combining information from various sources. The combined analysis of optical and microwave imagery uses the ad- vantages of both systems for vegetation classification.

\section{Field Observation and Validation of Results}

Another method is field observation and validation of results. Field observations are vital in remote sensing. In our research, the data collection stage prior to validation of the results of supervised classifications includes two categories of surveying methods, random (probabilistic) methods and empirical (non-random) methods. The survey was based on the satellite imaging document. Point sampling was used during this data processing stage. For each class, 1000 training points and 1000 control points (not the same points) were randomly chosen. This survey determines whether an observation unit belongs to a sample by random draw. In this case, the probability law is known. The random draw is stratified starting from all the homogeneous thematic areas. The stratification was initially performed prior to the field investigation phase. This first stage stratification is a morphological stratification that relies on textural homogeneity, backscattering and thematic homogenization criteria. As concerns field observations, the ground surveys (twenty floristic surveys per thematic class) carried out in the restored delta areas allowed us to determine the vegetation typology in the surveyed area. Vegetation description is physiognomic and includes land cover rate estimation. Depending on the size of the homogeneous area, the size of the observation unit is more or less significant. The vegetation structure and type were measured at each point within a $100-\mathrm{m}$ radius of the observer. Some floristic information was also gathered, including a list of species classified by physiognomic layers (trees, shrubs, and grasses).

The results of the evaluation are summarized in a confusion matrix. Based on the confusion matrix, statistical accuracy parameters are calculated. One is the overall accuracy, which counts pixels that are correctly classified in the reference divided by all pixels that are taken for reference. This procedure is used for both optical and microwave image classification.

\section{Remote sensing and restoration areas in the Danube Delta}

The results of this study relate to combinations of data from different satellite sensors (Sentinel-1 time series, Sentinel-2) that are used to improve the accuracy of recognition and mapping of major vegetation classes in the restoring areas in the Danube Delta. First, the data from each sensor are classified and analyzed. The results show quite good classification performance $(87.5 \%$ mean accuracy for Sentinel-2; 95.7\% for the Sentinel-1 time series) in this first step. The combination of the Sentinel-
2 time series and optical data from Sentinel-2 improved the performance of the classification (97.1\%) (Figure 4).

The vegetation types were labeled according to 10 classes (figures classifications). These classifications allowed us to distinguish several classes of reeds in the "large marsh vegetation' class (reed vegetation on salinized soils, pure reed vegetation, and reed vegetation on open plaur (floating vegetation called plaur (floating reed bed) is an association of reeds and other wetland plants that grow on a one- meter thick cover made up of roots, soil and various organic materials) and two classes of reed vegetation on compact plaur (one class with cut reeds).

The classification accuracy of the Sentinel-2 image (Figure 15) was estimated to be $87.5 \%$, which was inferior to that of the time series from the radar data provided by Sentinel-1. The Sentinel-1 images time series classifications (95.7\% mean accuracy) display very good accuracy.

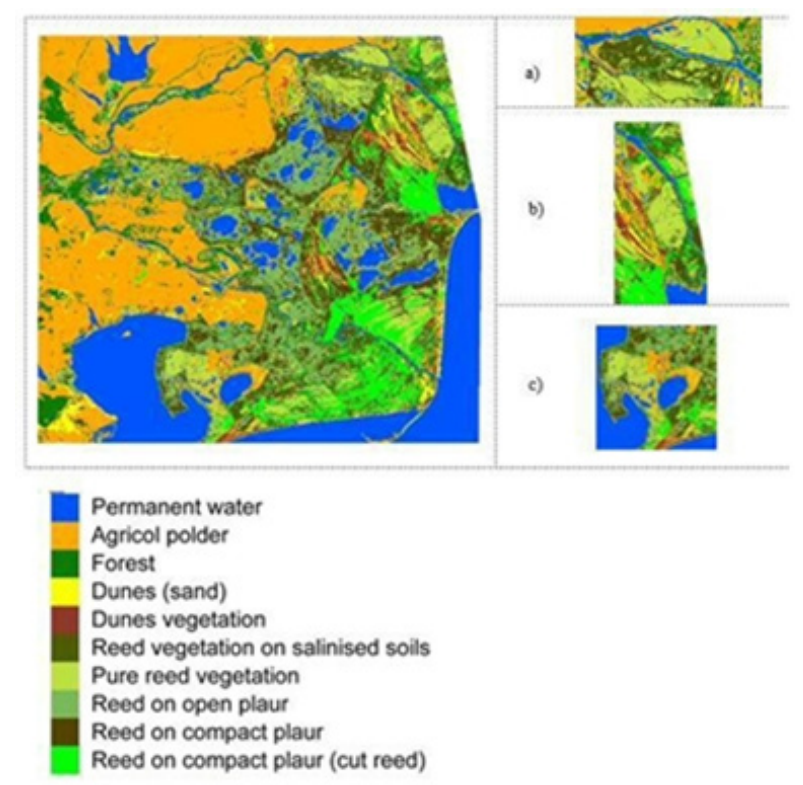

Figure 3: Random Forest classification in 10 classes vegetation: Optical image Sen- tinel-2. 5 classes of reed vegetation with some confusion between these classes. The restored areas: a) Babina-Cernovca; b) Popina; c) Dranov-Holbina.

The classification precision analysis per class proves that the Sentinel-2 images allow the identification of all 10 classes of vegetation considered in this study. The following classes exhibit satisfactory accuracy for some of the restoring areas: reed vegetation on salinized soils $(81.4 \%)$, pure reed vegetation $(76.9 \%)$, reed vegetation on open plaur $(87.3 \%)$. On the other hand, the class 'reed on compact plaur' exhibited lower performance in the mapping results, yielding an accuracy of $59.7 \%$. 


\begin{tabular}{|l|c|}
\hline Class & $\begin{array}{c}\text { Sentinel-2 } \\
\text { Per cent } \\
\text { accuracy }\end{array}$ \\
\hline $\mathbf{1}$ & 100.0 \\
\hline $\mathbf{2}$ & 91.5 \\
\hline $\mathbf{3}$ & 90.0 \\
\hline $\mathbf{4}$ & 98.4 \\
\hline $\mathbf{5}$ & 94.4 \\
\hline $\mathbf{6}$ & 81.4 \\
\hline $\mathbf{7}$ & 76.9 \\
\hline $\mathbf{8}$ & 87.3 \\
\hline $\mathbf{9}$ & 59.7 \\
\hline $\mathbf{1 0}$ & 96.4 \\
\hline Mean & $\mathbf{8 7 . 5 7 6}$ \\
\hline
\end{tabular}

Table 3: Performance of the classification by class and all classes of the Sentinel-2

By integrating the Sentinel-1 time series with optical images such as Sentinel-2, the quality of the habitat maps of the restoring areas in the Danube Delta can be considerably improved (Figure 4).

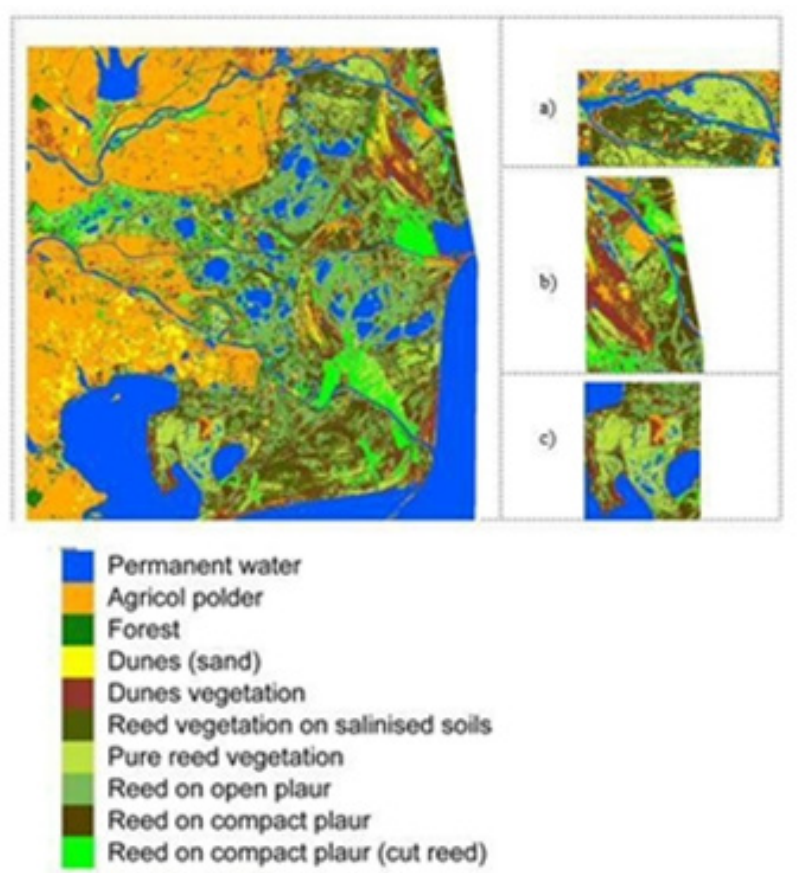

Figure 4: Multi-sensor data integration Sentinel-1 radar time series and Sentinel-2 optical sensor.5 classes of reed vegetation and less confusion between these classes. The restored areas: a) Babina-Cernovca; b) Popina; c) Dranov-Holbina.

Data integration between the Sentinel-1 and Sentinel-2 images provides classification with an overall accuracy of $97.1 \%$ and very good class accuracies ranging from $90.3 \%$ to $95.8 \%$. The classes 'reed vegetation on salinized soils' (97.1\%), 'pure reed vegetation' (91.1\%), 'reed on open plaur' (97.9\%), and 'reed on compact plaur' (cut reed) (99.9\%) were well mapped and show good accuracy (table 4 and Figure 5).

\begin{tabular}{|l|l|l|}
\hline Class & $\begin{array}{c}\text { Sentinel-1 } \\
\text { Per cent } \\
\text { accuracy }\end{array}$ & $\begin{array}{c}\text { Radar+optical } \\
\text { Per cent accu- } \\
\text { racy }\end{array}$ \\
\hline $\mathbf{1}$ & 99.5 & 99.8 \\
\hline $\mathbf{2}$ & 95.1 & 98.3 \\
\hline $\mathbf{3}$ & 96.4 & 98.1 \\
\hline $\mathbf{4}$ & 94.5 & 99.6 \\
\hline $\mathbf{5}$ & 96.8 & 99.5 \\
\hline $\mathbf{6}$ & 96.8 & 97.1 \\
\hline $\mathbf{7}$ & 92.1 & 91.1 \\
\hline $\mathbf{8}$ & 96.7 & 97.9 \\
\hline $\mathbf{9}$ & 91.5 & 90.3 \\
\hline $\mathbf{1 0}$ & 99.4 & 99.9 \\
\hline Mean & $\mathbf{9 5 . 8 7}$ & $\mathbf{9 7 . 1 5 1}$ \\
\hline
\end{tabular}

Table 4: Performance of the classification by class and all classes of multi-sensors and time series of Sentinel-1

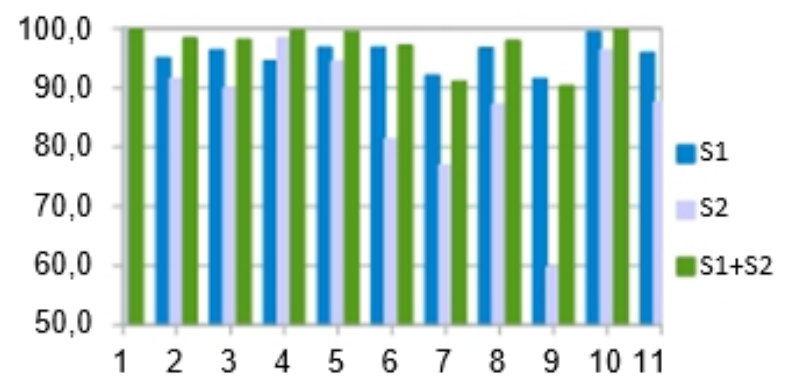

Figure 5: Performance for the multi-sensor and time series classification by class (per cent accuracy) $(\mathrm{S} 1=$ radar sensor time series Sentinel-1, S2=optical sensor Sen- tinel-2 and $\mathrm{S} 1+\mathrm{S} 2=$ multi-sensor data integration)

The mapping accuracies were summarized using confusion matrices and statistics including user, producer and overall accuracy and Cohen's K (Figure 6). Classification accuracy was assessed using global and Kappa indices. Very good Kappa indices were obtained; for the optical data, the Kappa index was 0.86, and for the multi-sensor data integration, the Kappa index was 0.96 . The classification accuracy was estimated using crossvalidation and by calculating the percentage of correctly classified pixels on the resulting maps. These present the reference class labels in rows and the labels predicted by the classifier in columns. The results are expressed in percentages with respect to the reference labels, and therefore, values in the diagonal represent Producers Accuracy. 


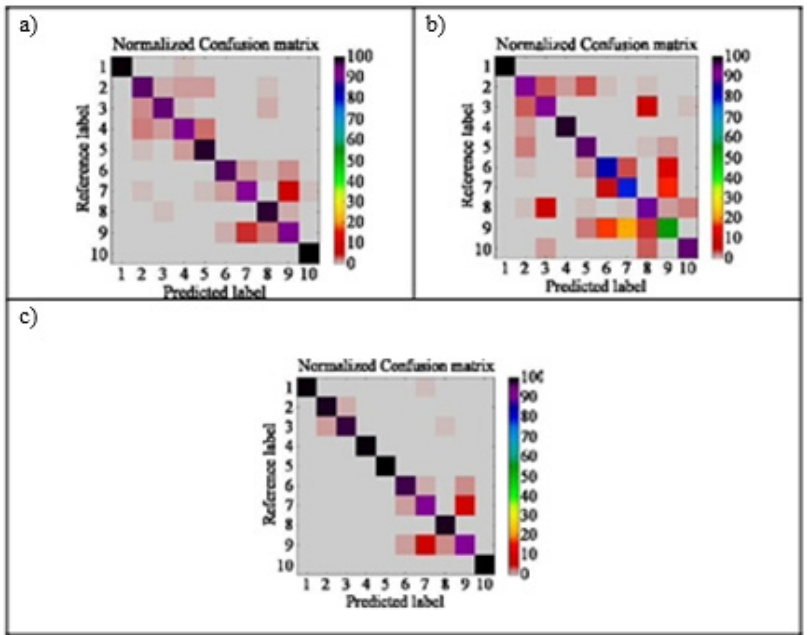

Figure 6: Confusion Matrix of Random Forest classifications: a) Sentinel-1 time series; b) optical data Sentinel-2; c) Multisensor data integration. Very good Producers Accuracy values for the confusion matrix of Sentinel-1 radar: most classes show values ranging from $90.01 \%$ to $99.72 \%$. The confusion matrix of optical data with many confusions of reed class. The confusion matrix of the multi-sensor data integration: the Producers Accuracy rates were higher than $90 \%$, i.e. ranging from 90.4 to $99.91 \%$.

Figure 6 shows the confusion matrix for the optical data. The matrix reveals many confusions of reed classes involving different forms (reed on salinized soils, pure reed, reed on compact plaur). The most important confusions concern the various reed classes that characterize the habitats in the restored areas. 'Reed on com- pact plaur' has a Producers Accuracy of 55.1\%, with confusions with the 'pure reed vegetation' class $(16.26 \%)$ and the 'reed vegetation on salinized soils' class $(10.42 \%)$. Other confusions concern the 'pure reed vegetation' class, which displays a Producers Accuracy of $78.65 \%$. The most important confusion in this class, $21.50 \%$, is represented by the 'reed on compact plaur' class. Thu, even when optical data are used, the distinction between the plant formations of these wetlands is not always easy. Prior research has revealed that when optical imaging is used there is spectral confusion between wet and dry environments and also between various types of wetlands. Marsh and swamp identification in the spring usually causes fewer problems than identification of wetlands with drier water regimes, such as peat bogs or swamps with considerable foliar biomass (Ozesmi and Bauer, 2002).

The confusion matrix of the classification resulting from the Sentinel-1 time series processing reveals very good Producers Accuracy values; most classes show values ranging from $90.01 \%$ to $99.72 \%$. The most substantial confusions concern the 'pure reed vegetation class', with a Producers Accuracy of $90.01 \%$. This class is mixed with the 'reed on compact plaur' class $(4.21 \%)$ and with the 'reed vegetation on salinized soils' class $(1.26 \%)$. Radar data provide information especially on plant physiognomies. This analysis supplies information on polarimetric data in relation to the geometric characteristics of the physiognomies of the plants growing in the restored areas of the delta and enables us to draw conclusions about ways to distinguish among the various plant physiognomies.

Finally, the confusion matrix of the multi-sensor data integration revealed excel- lent classification results when the Producers Accuracy rates were higher than $90 \%$, i.e., between 90.4 and $99.91 \%$. The low confusion values shown by this matrix concern the two classes for which we also read confusions.

\section{Temporal Intensity Radar Data Signature}

Our analysis will primarily address the different reed classes (Figures 7 and 8).

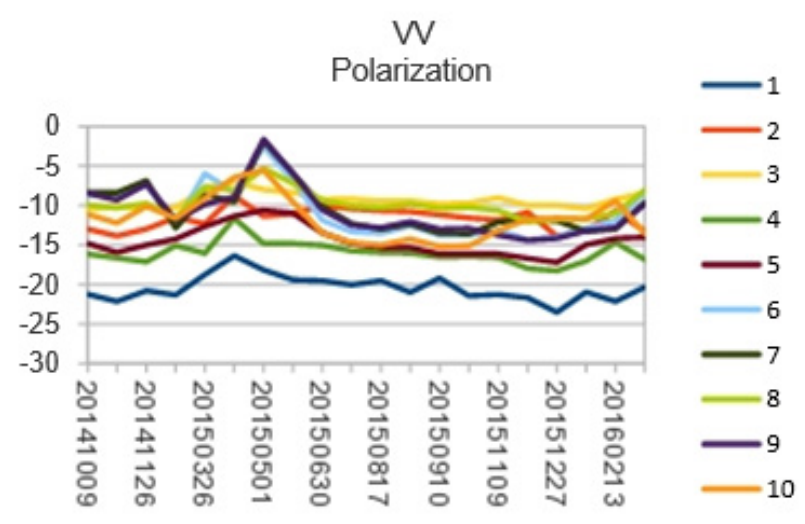

Figure 7: Temporal Intensity Radar Data Signature. Polarization VV

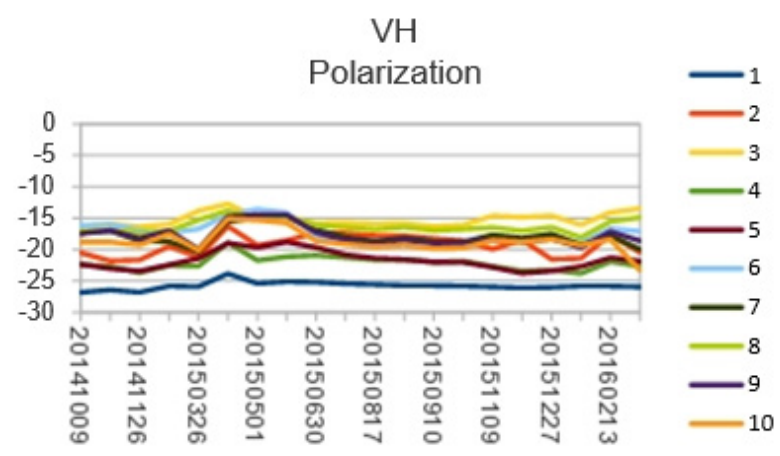

Figure 8: Temporal Intensity Radar Data Signature. Polarization $\mathrm{VH}$

On average, the temporal variation is similar whatever the polarization, VV or VH; from 2014 November to 2015 January, the radiometry is not really changing because at this period the landscape is not changing very much. In March in early spring, the different reed sites are characterized by surface backscattering with poor symmetric backscattering values. This surface backscattering is supported by the low intensity values of the VV polarization channel. The polarization channel values increase between late April and early June, indicating a transition from surface backscattering to dipolar backscattering. Between early June and late September, this dominant dipolar backscattering becomes almost representative of the total backscattering. In April and May, the backscattering values of different reed sites increase significantly due to the combined action of 
mature biomass and denser and taller vegetation. The decrease in the water level from $\approx 2 \mathrm{~m}$ to $\approx 1 \mathrm{~m}$ between July and August-September also accounts for this backscattering decrease. Signal saturation in band $\mathrm{C}$ and the difficult substrate access, due to water drainage at most of the sites, led to a decrease in all the intensity parameters. The main backscattering source thus shifts towards the upper part of the canopy, where the large, raised reed leaves enhance rather than reduce signal backscattering. An important observation concerns the temporal evolution of backscattering. We noted that the backscattering peak is reached when consistent backscattering mechanisms are in place (in May/June), correlating with the increased aerial biomass.

The foregoing observations show that there is a transition from surface backscattering in early spring, during which the first plant growth phase occurs (May-June), to dipolar or double-bounce non-dominant backscattering. This mechanism continues to be dominant during the second phase (July-August) up to plant maturity; it then turns into volume backscattering during the senescence phase.

On VH polarization, the species of the various reed classes make up a very homogeneous group, and there are few differences between the various seasonal sig- natures. For these classes, the backscattered power peak is reached in May and June, when consistent backscattering mechanisms are in place and the aerial biomass reaches its peak height.

\section{Conclusion}

According to research conducted by the United Nations Environment Programme, 40\% of the global economy depends on the proper functioning of ecosystems. In most cases, the ecosystem that needs restoring has been degraded, dam- aged, transformed or completely destroyed as a direct or indirect result of human actions. Ecological restoration should become a priority so as to limit the process of degradation of the environment, to contribute to the preservation of fragile habitats and of critically endangered species and to ensure the valorization of natural resources. Over time, human intervention has manifested itself in more than a quarter of the entire surface of the Danube. This intervention was brutal and has rendered ecosystem restoration very difficult. Over time, the development of fluvial-maritime navigation and of resource use policies applying to the Danube Delta (fish, agricultural, forestry, and other resources) has determined the main water system and landscape transformations in the Danube Delta.

After the fall of the communist regime, ecologic restoration actions were con- ducted in the delta. This ecologic reconstruction policy concerns all the dammed areas $(27.6 \%$ of the current surface area of the delta) that had been previously developed for agriculture, fish farming and reed processing. Considering that the Danube Delta includes 30 types of ecosystems that are highly dependent on river level oscillation, the main objective of this ecological recovery is to restore the natural hydrological circuit of the economically developed areas. A solution to these efforts of reconnection to the hydrological regime of the delta was suggested in 1994; it consisted of digging holes in the dykes to allow the water to enter and flow freely in these dammed areas. For the observation and analysis of the restored ecosystems in these areas, we relied on state-ofthe-art Sentinel-1 and Sentinel-2 radar and optical satellite imaging and remote sensing methodology. Remote sensing offers ac- curate automated methods for detecting change in restored wetlands. Vegetation change detection is a powerful indicator of restoration success. The restoration pro- jects use vegetative cover as an important indicator of restoration success. Our re- search, which relies on several series of radar images captured especially during the growth period, enables us to improve plant formation recognition by exploiting the temporal dynamics of the various plant classes of the restored areas of the delta. Temporal analyses revealed that no single date allows satisfactory characterization of all the vegetation classes. Thus, the temporal dimension, which is represented by seasonal evolution, is an essential component if we intend to draw up a detailed inventory of the restored vegetation classes in the delta.

The synergy of a time series of radar satellite observations with the optical data and radar data can be exploited to improve monitoring and analyze the vegetation in the restoration areas of the Danube Delta. Information from different sensors may assist in the variable retrieval by limiting potential ambiguities. The temporal resolution of the optical sensor Sentinel-2 does not provide temporally frequent products of vegetation characteristics due to the cloud coverage. Application of a multi-temporal radar, multi-sensor approach to a temporal sequence of data acquired by different sensors can improve mapping and monitoring of vegetation state variables over time. By integrating the Sentinel-1 time series with optical images such as those obtained by Sentinel-2, the quality of the habitat maps of the restoring areas in the Danube Delta can be improved considerably (97.1\%). Very good Kappa in- dices were obtained; for the time series radar, the Kappa index was 0.96, and for multi-sensor data integration the Kappa index was 0.97. The reliable Producers Ac- curacy and K coefficient results prove the complementarity of the two satellites for the observation, analysis and spatial representation of the deltaic plant ecosystems. The Producers Accuracy analysis by class shows that the Sentinel-2 sensor has its limits concerning the detection of similar plant classes, such as, for example, the different classes of reed. Although this sensor detects these classes, the mapping precision is not always high (on some occasions, it is approximately $55 \%$ for the 'reed on compact plaur' class). In contrast, the use of a Sentinel-1 time series reveals an interesting $\mathrm{C}$ band radar time signature in the Danube Delta ecosystem. Moreover, the combination with Sentinel-2 data resulted in considerable reduction of the observed confusions for both Sentinel-1 and Sentinel2 with, for instance, a Producers Accuracy value of the 'reed on compact plaur' class of $90.46 \%$, as well as increased accuracy for other reed classes. 
As revealed by the data collected by the satellites used in our research, the plant cover of the restored areas appears to be normal and to consist of plant formations similar to those found in the natural areas of the delta. Therefore, we could conclude that plant ecosystem restoration in the Danube Delta has been successful.

\section{References}

Apan, A. A., S. R. Raine, and M. S. Paterson, 2002. Mapping and analysis of changes in the riparian landscape structure of the Lockyer Valley catch- ment, Queensland, Australia. Landscape and Urban Planning 59, 43-57.

Baillarin, S.J., Meygret, A., Dechoz, C., Petrucci, B., Lacherade, S., Tremas, T., Isola, C., Martimort, P., Spoto, F., 2012. Sentinel-2 level 1 products and image processing performances, in: 2012 IEEE International Geoscience and Remote Sensing Symposium, 70037006.

Bourgeau-Chavez, L.L.; Smith, K.B.; Brunzell, S.M.; Kasischke, E.S.; Romanowicz, E.A., and Richardson, C.J., 2005. Remote monitoring of re- gional inundation patterns and hydroperiod in the Greater Everglades

Guo, Q., and N. P. Psuty, 1997, Flood-tide deltaic wetlands: detection of their sequential spatial evolution. Photogrammetric Engineering and Remote Sensing 63, 273-280.

Heinl, M., A. Neuenschwander, J. Sliva, and C. Vanderpost, 2006. Interactions be- tween fire and flooding in a southern Africa floodplain system (Okavango Delta, Botswana). Landscape Ecology 21, 699709.

Hütt, C., Koppe, W., Miao, Y., Bareth, G., 2016. Best Accuracy Land Use/Land Cover (LULC) Classification to Derive Crop Types Using Multitem- poral, Multisensor, and Multi-Polarization SAR Satellite Images. Re- mote Sensing 8.

Inglada, J., Vincent, A., Arias, M., Marais-Sicre, C., 2016. Improved Early Crop Type Identification By Joint Use of High Temporal Resolution SAR And Optical Image Time Series. Remote Sensing 8, 362.

Jensen, J. R., 2000. Remote sensing of the environment: an earth resource perspective, 2nd edition. Prentice Hall, Upper Saddle River, New Jersey.

Jensen, J. R., K. Rutchey, M. S. Koch, and S. Narumalani, 1995. Inland wetland change detection in the Everglades Water Conservation.

Klemas V., 2013, Using Remote Sensing to Select and Monitor Wetland Restoration Sites: An Overview. Journal of Coastal Research: Volume 29, Issue 4, 958 970.

Lang, M.W. and McCarty, G.W., 2008. Remote sensing data for regional wetland mapping in the United States: trends and future prospects. In: Russo, R.E. (ed.), Wetlands: Ecology, Conservation and Restoration. Hauppauge, New York: Nova, 1-40.
Michener, W. K., and P. F. Houhoulis, 1997. Detection of vegetation changes associated with extensive flooding in a forested ecosystem. Photogrammetric Engineering and Remote Sensing 63, 1363-1374.

Niculescu S., Lardeux C., Hanganu J., Mercier G., David L., Change Detection of Floodable in Danube delta by Radar Images, 2015, Natural Hazards, Vol- ume 78, Issue 3, 1899-1916.

Niculescu S., Pécaud D., Michèle-Guillou E., Soare P., L. David, 2015, Quel développement durable pour le delta du Danube ? Enquête à Pardina, Ver- tigO, Vol 15, n 1 , 2-26.

Niculescu, S., Lardeux, C., Grigoras, I., Hanganu, J., David, L., 2016. Synergy Be- tween LiDAR, RADARSAT-2, and Spot-5 Images for the Detection and Mapping of Wetland Vegetation in the Danube Delta. IEEE Journal of Selected Topics in Applied Earth Observations and Remote Sensing, 9, 3651-3666.

Novo, E.M.L.M.; Costa, M.P.F.; Mantovani, J.E. and Lima, I.B.T., 2002. Relation- ship between macrophyte stand variables and radar backscatter at $\mathrm{L}$ and $\mathrm{C}$ band, Tucurui reservoir, Brasil. International Journal of Remote Sens- ing, 23, 1241-1260.

Ozesmi, S.L. and Bauer, M.E., 2002. Satellite remote sensing of wetlands. Wetland Ecology and Management, 10, 381-402.

Papa, F., Prigent C., Durand F., and Rossow W. B., 2006. Wetland dynamics using a suite of satellite observations: a case study of application and evaluation for the Indian Subcontinent. Geophysical Research Letters 33:4.

Phinn, S. R., D. A. Stow, and D. V. Mouwerik, 1999. Remotely sensed estimates of vegetation structural characteristics in restored wetlands, Southern California. Photogrammetric Engineering and Remote Sensing 65, 485-493.

Ramsey, E. W. III, G. A. Nelson, and S. K. Sapkota, 1998. Classifying coastal re- sources by integrating optical and radar imagery and color infrared photography. Mangroves and Salt Marshes 2, 109-119.

Rodriguez-Galiano, V.F.; Ghimire, B.; Rogan, J.; ChicaOlmo, M.; Rigol-Sanchez, J.P., 2012, An assessment of the effectiveness of a random forest classifier for landcover classification, ISPRS J. Photogramm. Remote Sens., 67, 93-104.

Rosso, P. H., S. L. Ustin, and A. Hastings. 2005, Use of lidar to study changes associated with Spartina invasion in San Francisco Bay marshes. Remote Sensing of Environment 100, 295-306.

Shuman, C. S., and R. F. Ambrose, 2003, A comparison oremote sensing and ground-based methods for monitoring wetland restoration success. Restoration Ecology 11, 325-333. 
Simenstad, C., D. Reed, and M. Ford, 2006, When is restoration not? Incorporating landscape-scale processes to restore self-sustaining ecosystems in coastal wetland restoration, Ecological Engineering 26, 27-39.

Tuxen, K.A., Schile, L.M., Kelly, M., Siegel, S.W., 2008. Vegetation Colonization in a Restoring Tidal Marsh: A Remote Sensing Approach. Restoration Ecology 16, 313-323.

Zedler, J.B., Kercher, S., 2005, Wetland resources: status, trends, ecosystem services, and restorability. Annu. Rev. Environ. Resour. 30, 39-74 